\title{
¿POR QUÉ IMPORTA LA FILOSOFÍA EN LA EDUCACIÓN ESCOLAR PARA EL SIGLO XXI? COMENTARIO DE LA EXPOSICIÓN DE LA PROFESORA SYLVIA EYZAGUIRRE
}

\author{
Augusto Astudillo Cánobra \\ REPROFICH/ Colegio Extremadura \\ augustoastudillo@gmail.com
}

Agradezco a la Facultad de Filosofía y Humanidades de la Universidad de Chile la creación de este espacio de reflexión, que fue motivado por el profesor Jaime Araos. Si pretendemos desarrollar la presencia de la filosofía en la educación escolar necesitamos recrear instancias de pensamiento compartido y diálogo entre profesores de la universidad y la escuela. Este espacio da cuenta de que no necesitamos la amenaza de la desaparición de la filosofía en la escuela para generar el diálogo entre todos los actores de la filosofía chilena.

En primer lugar, quiero destacar la defensa que la profesora Sylvia Eyzaguirre realiza de la presencia de la filosofía en la educación básica de la escuela chilena. Considerando que nuestro Ministerio de Educación desde el año 2001 ha reiterado sus propuestas de exclusión de la filosofía en la escuela, resulta muy relevante que académicos con presencia en los medios expliquen a la opinión pública el valor de la filosofía para el desarrollo intelectual y moral del ser humano y, por ende, la necesidad de que los niños la practiquen desde los primeros años de su educación escolar. Como integrantes de la Red de Profesores de Filosofía de Chile, Reprofich, compartimos plenamente las palabras de la profesora Eyzaguirre, cuando señala: "Es un desafío para nuestro país avanzar en el desarrollo de habilidades cognitivas más complejas y la filosofía puede jugar un rol esencial en ello...introduciendo la asignatura tempranamente en el currículo escolar nacional" (Eyzaguirre 2018, p. 1). Este propósito concuerda plenamente con el principio que plantea la Reprofich en su Constitución: Filosofía se debe incorporar en la escuela desde primero básico ${ }^{1}$.

Iniciemos la tarea que nos ha convocado; comentar la exposición de la profesora Eyzaguirre respecto al rol de la filosofía en el desarrollo del pensamiento crítico. En su exposición ella nos ofreció una visión ampliada del aporte que hace la filosofía en la educación escolar, en especial cuando se cultiva desde la enseñanza básica. La ponencia de la profesora Eyzaguirre se estructura en torno a tres ejes que nos servirán para ordenar nuestro comentario:

1. La mirada utilitarista de la filosofía.

2. El aspecto político del quehacer filosófico en la escuela.

3. El pensamiento filosófico como facilitador de la formación humana. 
En cada uno de estos apartados compartiremos las ideas clave ofrecidas por nuestra expositora y planteamos reflexiones y preguntas que surgen de aquellos conceptos y de nuestra experiencia docente que ya suma 32 años.

\section{La mirada utilitarista}

La práctica de filosofía con niños genera crecimiento en diversos aspectos del desarrollo personal. Se potencia el ámbito cognitivo, moral y la actitud de búsqueda de sentido de la realidad. Las investigaciones en este ámbito no han tenido una amplia difusión; por esto constituyen un aporte significativo las conclusiones de investigaciones recientes que la profesora Eyzaguirre nos ofrece en su exposición. En diversos países se comprueba que la filosofía en la enseñanza básica desarrolla capacidades cognitivas de los estudiantes y genera mejores resultados en sus aprendizajes.

Podemos comentar que en nuestra experiencia docente lo habitual es que los directivos de la escuela o instituciones educativas centren su interés en los "resultados" prácticos que ofrece el cultivo de la filosofía en la educación básica. Como profesores -especialistas en educación-se espera que contemos con el respaldo de estudios serios que evidencian los avances de crecimiento reflexivo que ofrece la filosofía con niños. Los resultados de las investigaciones referidas debe llamar a una reflexión en torno al "valor" que aporta la filosofía en el desarrollo de la persona. No podemos olvidar que el avance intelectual es uno, entre muchos, de los objetivos de la educación. En una sociedad donde el Presidente declara que "la educación es un bien de consumo" resulta muy atractivo que una asignatura ofrezca mejores resultados en los puntajes del SIMCE y la PSU. La visión reduccionista, habitual en padres y apoderados, es que se contratan servicios educativos (en la escuela) para obtener un pase para contratar la obtención de un título profesional (en la universidad). Bajo esa perspectiva, la filosofía con niños es eficiente y rentable. ¡Cuidado con enamorarnos de esta visión utilitarista! El riesgo para los profesores de la especialidad es evidente; "Vendo asignatura entretenida que produce buenos puntajes en pruebas estandarizadas". ¿Nos hemos convertido en vendedores de nuestro ramo?

La profesora Eyzaguirre nos recuerda que además del positivo impacto en el área cognitiva, la "mirada útil" incorpora otro aspecto que no se destaca debidamente del programa de filosofía con niños; el desarrollo de habilidades "blandas". En estas habilidades se encuentran la escucha activa, la búsqueda del diálogo, la capacidad de argumentar y la mejoría en la autoestima.

Nos podemos preguntar: ¿Acaso estas habilidades son menos importantes que las habilidades "duras"? ¿La búsqueda del diálogo tiene menor importancia que resolver una ecuación? ¿Es más valioso el desarrollo de la autoestima que definir un término con precisión? Las mal llamadas habilidades blandas son tanto o más relevantes para el desarrollo personal y colectivo. No olvidemos que el concepto de inteligencia emocional, aportado por Daniel Goleman, amplió la perspectiva del desarrollo personal. 


\section{La utilidad - inutilidad de la filosofía}

A partir de la consideración del aspecto útil de la presencia de la filosofía en la enseñanza básica nos parece pertinente una referencia a la antigua discusión sobre la utilidad de la filosofía -en sí misma- más allá de su presencia en la escuela. A pesar de que la mayoría de los filósofos se han referido a este aspecto y parece consagrada la "inutilidad" de nuestra ciencia, nos parece fundamental motivar una nueva reflexión en torno a qué entendemos por utilidad o inutilidad. La idea canonizada sobre la inutilidad de nuestro saber filosófico nos parece ambigua y peligrosa. Más allá de búsquedas etimológicas y referencias a los clásicos, la proclamación (un poco soberbia) de la inutilidad de la filosofía genera equívocos. Es posible que los productores de filosofía no hayan logrado traspasar el significado profundo de esta inutilidad y, por ende, el ciudadano de a pie lo entienda como aquello que no tiene valor e importancia. En esta línea podemos imaginar una autoridad ministerial haciendo este razonamiento: "Lo inútil no sirve, no aporta. Conclusión: Una disciplina inútil no merece espacio en el currículum escolar, donde hay tantas ciencias duras que deben ocupar la mente de los estudiantes".

\section{El aspecto político}

La profesora Eyzaguirre se pregunta ¿qué papel le cabe a la filosofía en la formación de ciudadanos? Nos responde a partir del rol político de la escuela como formadora de sujetos críticos y autónomos. En cuanto la vivencia de la democracia se basa en sujetos que se puedan gobernar desde la autonomía, que es fruto del cultivo del pensamiento crítico. Nos parece de la mayor trascendencia la importancia que la profesora Eyzaguirre le atribuye a la reflexión ética que propicia la filosofía. Un sujeto que se piensa como sujeto moral y se convierte en sujeto responsable ("respondiendo" por la razón de sus acciones) está mejor preparado para aportar en la vida democrática.

Nos surgen las preguntas. ¿Los profesores de filosofía hemos estado a la altura de esta tarea formadora? ¿Los temas éticos quedan como una materia que podría "verse" en cuarto medio o procuramos una reflexión profunda acerca de la moralidad propia y de la sociedad donde nos toca vivir? ¿Estamos reproduciendo de manera acrítica un sistema político económico que tiende a la uniformidad y el cansancio? -como indica ByungChul $\mathrm{Han}^{2}$ - o ¿estimulamos el hábito de buscar respuestas con criterio racional? Vayamos a una situación cotidiana en nuestras clases: ¿cómo recibimos las críticas y sugerencias de nuestros estudiantes? No podemos obviar esta pregunta cuando muchas veces detrás del "profe buena onda" se esconde un pequeño dictador que se las arregla para hacer las cosas a su manera, sin considerar el criterio y la sensibilidad de sus alumnos. Como explicación (¿o justificación?) podemos plantear que nuestro sistema escolar es rígido y jerarquizado, con pocos espacios de autonomía para generar propuestas innovadoras. El tiempo apremia, hay que colocar notas, entregar el informe 
a los apoderados, no has terminado de planificar, tienes pendiente enviar la guía a imprimir, etc. No hay espacio para sugerencias de los alumnos ni la posibilidad de trabajo colaborativo. La vida escolar, estructurada de manera conductista entre timbres pavlovianos que no dejan de sonar, es un espacio donde lo urgente no deja espacio a lo importante. Peor aún, muchas veces los profesores vuelven a un estado premoral cuando, para no perder el trabajo, van en contra de los principios mínimos de autonomía profesional y dignidad personal.

En un país que ya no reacciona a las tropelías éticas y las acciones inmorales que vienen de instituciones que se presentaban como los custodios de la moral, se convierte en tarea urgente afinar el oído ético, como nos sugiere Fernando Savater (1993, p. 34). Si no ponemos un fuerte acento en el desarrollo moral, en una sociedad donde campea la estafa y la corrupción en todos los niveles, solo nos quedaría gritar con fuerza: "iSálvese quien pueda!”

\section{Dimensión ética de la filosofía con niños}

Queremos destacar que el programa de Filosofía con Niños más desarrollado en Chile desde la década de 1990 es el de Matthew Lipman (Eyzaguirre 2018, p. 8), que enfatiza que además del progreso cognitivo, el cultivo de la filosofía por parte de los niños los dispone hacia una valoración de la diversidad y un respeto a todo sujeto. Los niños que hacen filosofía reconocen en sus compañeros de aula a personas válidas -aunque piensen distinto- y buscarán acuerdos a partir de los mejores argumentos que surjan en su "comunidad de indagación" democrática y la resolución de conflictos por la vía de acuerdos con fundamentación racional.

\section{Formación humana y desarrollo personal más profundo}

En su artículo, la profesora Eyzaguirre plantea que la filosofía "[p]ermite abordar cuestiones fundamentales para el desarrollo humano y la formación ciudadana, la pregunta por la realidad, la verdad y el conocimiento (epistemología), por el bien y la justicia (ética) y por nuestra propia existencia (antropología filosófica y ontología)" (Eyzaguirre 2018, p. 1).En la ponencia aporta el contexto que justifican estas tareas filosóficas. En un mundo en constante transformación donde la ciencia y la tecnología generan posibilidades impensadas hace pocos años, se hace necesaria la filosofía, fomentando la curiosidad que nos lleva a realizar las preguntas esenciales. ¿Quién soy yo?, ¿para qué estoy en el mundo?

Ámbito de discusión grupal donde se buscan soluciones a problemas que los estudiantes consideran relevantes. 
Por nuestra parte nos resurge la pregunta clave, ya planteada por Kant: ¿Enseñamos filosofía o enseñamos a filosofar? Asumiendo que la filosofía supone una mirada más profunda acerca de la realidad, donde cuestionamos el origen y el sentido, nuestras clases no pueden ser visitas al museo sino que deben convertirse en una fiesta del pensamiento, que se abre a sus múltiples posibilidades. Muchas veces los profesores de filosofía nos quedamos en declaraciones de buenas intenciones y no llevamos al aula las múltiples y luminosas posibilidades de la filosofía. ¡Tarea pendiente!

\section{La pregunta permanente}

En la exposición de la profesora Eyzaguirre hay una pregunta que es el substrato de toda su reflexión: ¿qué es la filosofía?, ¿cuál es su objetivo? Obviamente en este espacio no vamos a llegar a un acuerdo. Un aspecto de la mayor relevancia de la irrupción de la $\mathrm{FcN}$ en el mundo, es que abre un debate que, a nuestro parecer, no se ha sistematizado en Chile: ¿cuál es la esencia de la filosofía?, ¿quién puede practicarla? $\mathrm{FcN}$ nos da una respuesta que rompe con el paradigma de la filosofía clásica. La filosofía ya no es campo cerrado para los adultos, para quienes supuestamente tienen la mayor capacidad reflexiva. Hace 50 años se instaló otra mirada que tiene a los niños haciendo reflexiones filosóficas. Imposible no recordar a Jaspers afirmando que los niños son, por naturaleza, filósofos. Tenemos una tarea pendiente: abrir el debate respecto a qué es hoy la filosofía.

\section{Maestras y maestros inspiradores}

El camino de la Filosofía con Niños en nuestro país ha tenido maestros y maestras que con sabiduría y generosidad han compartido su saber teórico y práctico a cientos de profesores de la escuela. En la facultad que alberga este coloquio tenemos a la profesora Olga Grau, un ejemplo de dedicación y pasión por la $\mathrm{FcN}$ que ha fomentado el encuentro entre educadores de la universidad y la escuela. En Argentina destacan Walter Kohan y Alejandro Cerletti, cuyas reflexiones y espacios de enseñanza han contribuido a una $\mathrm{FcN}$ situada en el contexto de la escuela latinoamericana. Cierro este comentario con las palabras de los autores mencionados: "La filosofía marca una diferencia. Hoy en día cuando hay tanta ambigüedad, confusión, ansiedad y falta de certeza sobre lo que podemos hacer y cómo vivir, la tarea filosófica de preguntar, poner en cuestión y pensar importa más que nunca" (Cerletti y Kohan 1997).

Con nuestro recuerdo y cariño permanente hacia Rosita Riquelme Andrades, integrante fundadora de Reprofich, fallecida el 20 de noviembre de 2018 
Referencias bibliográficas

Cerletti, Alejandro y Walter Kohan (1997), La filosofía en la escuela. Caminos para pensar su sentido. Buenos Aires: UBA.

Eyzaguirre, Sylvia (2018), "El rol de la filosofía en el desarrollo del pensamiento crítico", Puntos de Referencia $\mathrm{N}^{\circ} 485$, julio 2018. Santiago: Centro de Estudios Públicos.

Savater, Fernando (1993), Ética para amador. Madrid: Ed. Ariel. 